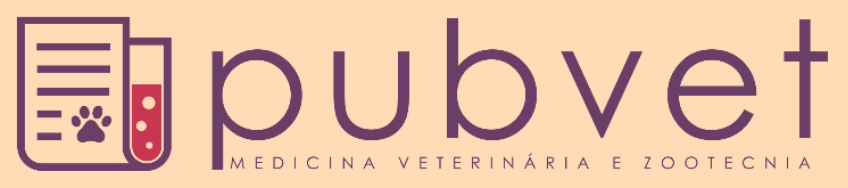

DOI:10.31533/pubvet.v12n10a182.1-5

\title{
Desenvolvimento orgânico da alface $c v$. Veneranda em diferentes canteiros e manejo de irrigação
}

\author{
Elton Carlos Pereira Vieira de Alencar Teles ${ }^{*} \bullet$, Daniel de Carvalho Leite ${ }^{2} \bullet$, Francisco

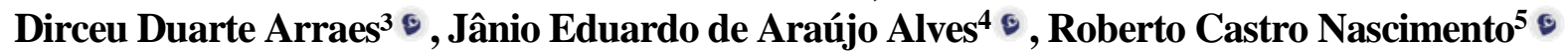 \\ ${ }^{{ }^{*}}$ Engenheiro Agrônomo, Mestre em Engenharia Agrícola, Universidade Federal do Vale do São Francisco. Juazeiro -BA Brasil. \\ ${ }^{2}$ Professor do Instituto Federal Educação, Ciência e Tecnologia Baiano-IFBA, campus Serrinha-BA, Brasil-E-mail: carvalho.leite@hotmail.com \\ ${ }^{3}$ Professor do Instituto Federal Educação, Ciência e Tecnologia Sertão Pernambucano - IF-Sertão-PE, campus Salgueiro-PE, Brasil \\ ${ }^{4}$ Técnico de Laboratório em Agroindústria do Instituto Federal do Sertão Pernambucano - IF-Sertão-PE, campus Salgueiro-PE, Brasil \\ ${ }^{5}$ Doutorando, Programa de Pós-graduação em Engenharia Agrícola, Universidade Federal do Recôncavo Baiano, Cruz das Almas-BA, Brasil \\ *Autor para correspondência, E-mail: eltonteles@hotmail.com
}

RESUMO. Objetivou-se com este trabalho avaliar o desenvolvimento da alface $c v$. Veneranda, em diferentes formas de irrigação em sistema orgânico de produção no semiárido Pernambucano. O presente estudo foi realizado na cidade de Salgueiro/PE, em uma propriedade rural de base familiar. Experimentalmente foram analisadas o desenvolvimento da alface orgânico irrigadas em canteiro econômico integrado ao sistema de irrigação cuca de umbu e canteiro convencional por meio da evapotranspiração de referência (ETo) diária estimado pelo método padrão de Penman-Monteith recomendado pela FAO, durante sete épocas de avaliação biométrica após o transplantio $(04 ; 08 ; 12 ; 16$; 20; 24 e 27 DAT). Ao final do ciclo (27 DAT) foram avaliados os dados biométricos e de consumo hídrico por tipo do manejo da irrigação. Os dados foram submetidos a análise de regressão polinomial. Os resultados mostraram que os parâmetros biométricos (número de folhas, altura e diâmetro da planta) foram superiores para o canteiro econômico, integrado ao sistema de irrigação cuca de umbu. No entanto, houve um consumo de 47,17 mm de água neste sistema de irrigação, quando comparado ao manejo da irrigação em canteiro convencional via ETo pelo método padrão de Penman-Monteith - FAO.

Palavras chave: semiárido, sustentável, vegetal

\section{Organic development of lettuce $c v$. Veneranda in different beds and irrigation management}

\begin{abstract}
The objective of this work was to evaluate the development of lettuce cv. Veneranda (Lactuca sativa L.) in different forms of irrigation in organic production system in the semi-arid Pernambucano. The present study was conducted in the city of Salgueiro/PE, in a family-owned rural property. Experimentally, it was analyzed the development of organic lettuce irrigated in an economical bed integrated to the umbu cuca irrigation system and conventional bed by means of the reference evapotranspiration (ETo) daily, estimated by the standard Penman-Monteith method recommended by FAO, during seven evaluation periods biometric after transplanting $(4 ; 8 ; 12 ; 16 ; 20 ; 24$ e 27 DAT). At the end of the cycle (27 DAT) the biometric and water consumption data by type of irrigation management were evaluated. After data collection, the data were submitted to polynomial regression analysis. The results showed that the biometric parameters (number of leaves, height and diameter of the plant) were higher for the economic bed, integrated umbu cuca irrigation system. However, there was a consumption of $47.17 \mathrm{~mm}$ of water in this irrigation system, when compared to the management of the irrigation in conventional beds through ETo by the Penman-Monteith standard method - FAO.
\end{abstract}

Keywords: vegetable, sustainable, blade, semi-arid 


\section{Desarrollo orgánico de la lechuga en diferentes viveros y manejo de irrigación}

RESUMEN. Se objetivó con este trabajo, evaluar el desarrollo de la alface cv. Veneranda (Lactuca sativa L.), en diferentes formas de irrigación en sistema orgánico de producción en el semiárido Pernambucano. El presente estudio se realizó en la ciudad de Salgueiro / $\mathrm{PE}$, en una propiedad rural de base familiar. En el presente trabajo se analizó el desarrollo de la lechuga orgánica irrigada en un vivero integrado al sistema de riego cuca de umbu y vivero convencional por medio de evapotranspiración de referencia (ETo) diaria, estimada por el método estándar de Penman-Monteith recomendado por la FAO, durante siete épocas de evaluación biométrica tras el trasplante $(04,08,12,16,20,24$ y 27 DAT). Al final del ciclo (27 DAT) se evaluaron los datos biométricos y de consumo hídrico por tipo del manejo de irrigación. Después de la recopilación, los datos fueron sometidos a análisis de regresión polinomial. Los resultados mostraron que los parámetros biométricos (número de hojas, altura y diámetro de la planta) fueron superiores en el vivero económico, integrado al sistema de irrigación cuca de umbu. Sin embargo, hubo un consumo de 47,17 $\mathrm{mm}$ de agua en este sistema de riego, en comparación al manejo del riego en vivero convencional vía ETo por el método estándar de Penman-Monteith - FAO.

Palabras clave: vegetal, sostenible, lámina, semiárido

\section{Introdução}

A alface (Lactuca sativa L.) originária das regiões mediterrâneas faz parte da família das Asteraceae e há séculos a humanidade cultiva e consome suas folhas, seja na forma de saladas ou em combinação com sanduíches (Favarato et al., 2017).

No Brasil, estima-se que a cultura da alface ocupe uma área cultivada de aproximadamente 35.000 ha, com predominância do grupo do tipo crespa (Juchen et al., 2013). Parte dessa área cultivada tem origem em propriedades que compõem um sistema de produção da agricultura familiar (Bonela et al., 2015), o que lhe confere um impacto econômico e social para essa base familiar (Costa et al., 2012). No entanto, o uso indiscriminado de defensivos e adubos químicos, tem provocado uma mudança na preferência dos consumidores quanto a forma de produção das hortaliças, tendo destaque os produtos de origem orgânica (Sediyama et al., 2014). Associado a essa problemática pelo uso desordenado dos produtos químicos nas lavouras, a alface é constituída por um alto teor de água, necessitando de uso da irrigação para sua produção.

As regiões áridas e semiáridas são caracterizadas pela escassez hídrica considerável, devido à baixa precipitação pluviométrica e sua distribuição irregular ao longo dos anos, o que impediria, em tese, o cultivo da alface nessas regiões. Nessa perspectiva, as pesquisas tecnológicas de convivência com o semiárido, desenvolveram um tipo de canteiro, denominado econômico, o qual poderia otimizar o uso da água nas regiões semiáridas. Partindo do princípio da tecnologia desenvolvida, Leite et al. (2011) desenvolveram um sistema de irrigação nomeado de cuca de umbu, que tem como principal função, melhorar a otimização da água nos canteiros econômicos. Nas pesquisas realizadas por Leite et al. (2011) com o uso dessa tecnologia integrativa, foi observado que a produção de mudas de alface teve uma eficiência de $45 \%$ quando comparado ao sistema de irrigação por micro aspersão.

Outra forma de otimizar o uso da água na irrigação em regiões áridas e semiáridas está baseada no monitoramento das informações climáticas, por meio da evapotranspiração de referência (ETo), com destaque para equação proposta por Penman-Monteith, considerado o método padrão da FAO.

Este trabalho foi realizado para avaliar desenvolvimento de alface cv. Veneranda, em diferentes manejos da irrigação em sistema orgânico de produção no semiárido Pernambucano.

\section{Material e Métodos}

O experimento foi conduzido no período de 1 de dezembro de 2017 a 17 de janeiro de 2018 em uma propriedade de base familiar no município de Salgueiro, sertão central de Pernambuco, situada a $8^{\circ} .01^{\prime} 56^{\prime \prime}$ de latitude de Sul e 39 13 '51" longitude Oeste do meridiano de Greenwich, com aproximadamente 420 metros de altitude. O clima 
local se enquadra de acordo com a classificação de Köppen adaptada para o Brasil, no tipo BSwh (semiárido e quente), com temperaturas médias anuais e pluviométricas de $25,3^{\circ} \mathrm{C}$ e $650 \mathrm{~mm}$, respectivamente. $\mathrm{O}$ solo da região foi classificado de acordo com Araújo Filho et al., (2000) como Latossolo Vermelho Amarelo de textura argilosa.

$\mathrm{O}$ delineamento experimental utilizado foi em blocos ao acaso e quatro repetições, sendo constituído por dois tipos de canteiros: (canteiro econômico), irrigado por meio de um condutor hidráulico via solo integrado ao sistema de irrigação cuca de umbu e (canteiro convencional) (Figura 1), irrigado pela ETo utilizando o método padrão de Penman-Monteith, durante sete épocas de avaliação biométrica após o transplantio (04; 08; 12; 16; 20; 24 e 27 DAT).

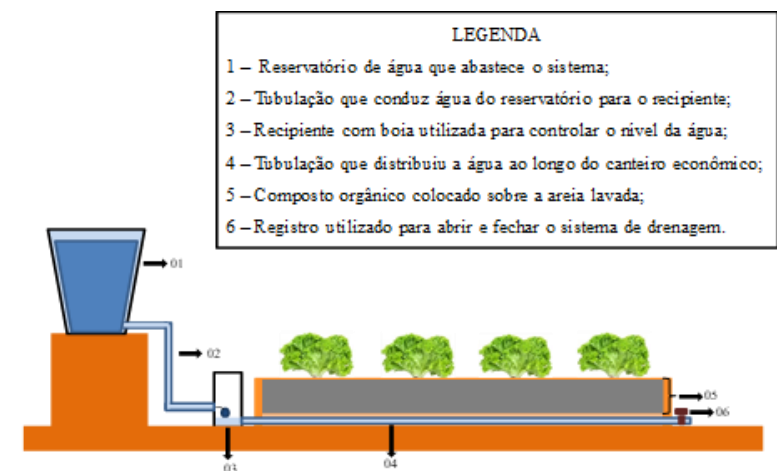

Figura 1. Esquema do canteiro econômico integrado ao sistema de irrigação cuca de umbu.

Os canteiros econômicos foram construídos com 2 metros de comprimento, 1 metro de largura e $18 \mathrm{~cm}$ de profundidade utilizando bloco, cimento e areia. Para evitar problemas de infiltração, os canteiros foram impermeabilizados com lonas plásticas dupla face (preta e branca) de 150 micras.

Para distribuição da água no seu interior foi utilizado um tubo de PVC de $32 \mathrm{~mm}$, perfurado com orifícios de seis milímetros de diâmetro (de um lado para o outro do tubo) a cada $20 \mathrm{~cm}$ e em seguida, coberto com telhas de cerâmica para evitar entupimentos. Para preenchimento foi utilizado areia lavada até cobrir o tubo de distribuição da água e completado com composto orgânico formado com materiais de serrapilheira e esterco bovino curtido na proporção de 3:1. Os canteiros convencionais, foram construídos um mês antes da realização desta pesquisa com 1 metro de largura, dois de comprimento e $20 \mathrm{~cm}$ de altura, com nivelamento em ambos os lados.

$\mathrm{O}$ vegetal utilizado neste experimento foi a alface crespa (Lactuca sativa L.) variedade veneranda, adquirida com a compra de sementes da empresa Feltrin, a qual tem como característica a resistência ao apendoamento e colheita entre 60 e 70 dias após a semeadura, apresentando folhas verde-claras, grandes e soltas.

Para a produção das mudas de alface foi realizado o semeio em recipientes plásticos com volume de $150 \mathrm{~mL}$ preenchidos com substrato formado por composto orgânico, serapilheira e esterco bovino, cujas características químicas foram realizadas no laboratório de análise de solos e plantas (LASP) e encontram-se na Tabela 1, em seguida, acondicionados em badejas de madeira impermeabilizadas com lona plástica que foram irrigadas de forma automática pelo sistema de irrigação cuca de umbu.

O transplante das mudas de alface veneranda para os canteiros foi realizado vinte e dois dias após a semeadura, quando as plantas atingiram quatro folhas definitivas e plantadas no espaçamento de $0,30 \times 0,30$ metros, conforme orientações da empresa produtora das sementes (Feltrin, 2017). Cada repetição foi constituída de três linhas de sete plantas, porém para efeito de análise dos dados, só foram consideradas as cinco plantas centrais de cada parcela descartando-se as plantas laterais.

A adubação dos canteiros econômicos e convencionais foi realizada 15 dias antes do transplante das hortaliças, seguindo as orientações de Souza \& Resende (2006) e utilizando materiais orgânicos existentes na propriedade.

Tabela 1. Caracterização química dos substratos (composto orgânico - C.O, serapilheira - S.P e esterco bovino - E.B

\begin{tabular}{|c|c|c|c|c|c|c|c|}
\hline Amostra $^{1}$ & $\mathrm{~N}$ & $\mathrm{P}$ & $\mathrm{K}$ & $\mathrm{Ca}$ & $\mathrm{Mg}$ & $\mathrm{C}$ & $\mathrm{C} / \mathrm{N}$ \\
\hline & \multicolumn{7}{|c|}{-----------Teor na matéria seca a $70^{\circ} \mathrm{C}(\mathrm{g} / \mathrm{kg})$} \\
\hline$\overline{\mathrm{C} . \mathrm{O}}$ & 10,2 & 2,25 & 5,50 & 10,6 & 9,1 & 191 & $19 / 1$ \\
\hline SP & 16,0 & 1,54 & 8,00 & 11,2 & 7,0 & 417 & $26 / 1$ \\
\hline E.B & 18 & 3,62 & 10,00 & 22,2 & 7,0 & 197 & $11 / 1$ \\
\hline
\end{tabular}

Fonte: Laboratório de Análises Solo e Plantas - Lasp, Petrolina/PE, 2017 
Neste caso foi adicionado a cada canteiro $2 \mathrm{~kg} \mathrm{~m}^{2}$ de esterco bovino e 3,6 $\mathrm{kg}$ de serrapilheira de restos de folhas e galhos decompostos de Pau Ferro (Caesalpina Ferrea Mart. ex Tul.), a qual é uma espécie pertencente à família das leguminosas, nativa do Brasil, de ocorrência na caatinga (Penna, 1946; Pio Corrêa, 1984; Lewis, 1987).

Apesar de já existir composto orgânico nos canteiros econômicos, a adubação com esterco bovino e serrapilheira serviu para repor os nutrientes perdidos em cultivos anteriores, uma vez que estes canteiros já eram utilizados para produção de hortaliças folhosas, como alface, cebolinha, couve e coentro.

Para minimizar a evaporação da água, a serrapilheira utilizada na adubação, não foi totalmente incorporada ao solo e parte dela ficou sobre a superfície do canteiro servindo como cobertura morta. O total de material orgânico utilizada, forneceu às plantas as seguintes quantidades de macronutrientes: $93,6 \mathrm{~g} \mathrm{~m}^{-2} \mathrm{de} \mathrm{N}$, $12,78 \mathrm{~g} \mathrm{~m}^{-2}$ de $\mathrm{P}, 48,8 \mathrm{~g} \mathrm{~m}^{-2}$ de $\mathrm{K}, 84,72 \mathrm{~g} \mathrm{~m}^{-2} \mathrm{de}$ $\mathrm{Ca}$, e $39,2 \mathrm{~g} \mathrm{~m}^{-2}$ de $\mathrm{Mg}$, conforme resultados da análise química do solo na profundidade de 0 a $20 \mathrm{~cm}$.

$\mathrm{O}$ manejo da irrigação nos canteiros convencionais foi realizado por meio da evapotranspiração de referência (ETo) diária, estimado pelo método padrão de PenmanMonteith recomendado pela FAO (Allen et al., 1998), conforme a equação (1).

$$
\begin{aligned}
& E T_{o} \\
& =\frac{0,408 \Delta\left(R_{n}-G\right)+\gamma \frac{900}{T_{m e ́ d}+273} u_{2} \frac{e_{s}-e_{a}}{10}}{\Delta+\gamma\left(1+0,34 u_{2}\right)}
\end{aligned}
$$

em que:

ETo - evapotranspiração de referência, $\mathrm{mm} \mathrm{dia}^{-1}$; $\Delta$ - declividade da curva de pressão de saturação, $\mathrm{KPa}^{\circ} \mathrm{C}^{-1}$; $\mathrm{Rn}$ - saldo de radiação, $\mathrm{MJ} \mathrm{m}^{-2} \mathrm{dia}^{-1}$;

$\mathrm{G}$ - fluxo de calor no solo, $\mathrm{MJ} \mathrm{m}^{-2} \mathrm{dia}^{-1}$;

$\gamma$ - constante psicrométrica, $\mathrm{kPa}^{\circ} \mathrm{C}^{-1}$;

Tméd - temperatura média diária do ar, ${ }^{\circ} \mathrm{C}$;

$\mathrm{u}_{2}$ - velocidade do vento a $2 \mathrm{~m}$ de altura, $\mathrm{m} \mathrm{s}^{-1}$; $\mathrm{e}_{\mathrm{s}}$ - pressão de saturação de vapor d'água, $\mathrm{kPa}$;

$\mathrm{e}_{\mathrm{a}}$ - pressão atual de vapor d'água, $\mathrm{kPa}$.

Os dados para estimar ETo foram fornecidos pelo Instituto Nacional de Meteorologia (INMET), através da estação meteorológica de superfície automática da cidade de Salgueiro/PE. A precipitação pluvial, foi obtida pelas informações por meio de um pluviômetro instalado na área experimental.

Para os canteiros econômicos, a irrigação foi realizada por gravidade de forma intermitente e a quantidade de água utilizada foi determinada através da reposição diária de um recipiente com capacidade para 30 litros e mantida durante todo ciclo uma lâmina de $0,06 \mathrm{~m}$ de profundidade dentro do canteiro, ficando $0,12 \mathrm{~m}$ de material orgânico servindo como condutor hidráulico. Para irrigação, foi utilizada como fonte hídrica, a água da chuva que era armazenada em uma cisterna calçadão com capacidade para $52 \mathrm{~m}^{3}$.

Temporalmente em, 04; 08; 12; 16; 20; 24 e 27 dias após o transplantio foram avaliadas as seguintes variáveis biométricas: número médio de folhas por planta, determinado manualmente contando-se o número de folhas com tamanho mínimo de dois centímetros; altura média de plantas $(\mathrm{cm})$, determinada medindo-se da altura do colo até o final da folha mais alta, utilizando-se uma régua graduada; e diâmetro da planta, determinado medindo-se o tamanho da área ocupada pela planta, utilizando-se uma régua graduada.

Os dados temporais de número de folhas, altura e diâmetro da planta, foram submetidos a análise de regressão polinomial, onde correlacionou-se os valores obtidos com os dias após o transplantio para cada canteiro e manejo da irrigação avaliado.

\section{Resultados e Discussão}

As informações de temperatura, umidade do ar, pressão, velocidade do vento foram monitorados pelo site do Instituto Nacional de Meteorologia (INMET), conforme mostra a Tabela 2.

Tabela 2. Média dos valores (máximo, mínimo e médios) da temperatura $\left({ }^{\circ} \mathrm{C}\right)$, umidade do ar $(\%)$, Pressão (hPa), velocidade do vento $(\mathrm{m} / \mathrm{s})$ e precipitação $(\mathrm{mm})$ ocorrida durante período experimental. Salgueiro, PE, 2018.

\begin{tabular}{lccccc}
\hline Valores & $\begin{array}{c}\text { Temperatura } \\
\left({ }^{\circ} \mathrm{C}\right)\end{array}$ & $\begin{array}{c}\text { Umidade } \\
\text { Relativa }(\%)\end{array}$ & Pressão (hPa) & Vento (m/s) & Precipitação (mm) \\
\hline Máximo & 29,87 & 50,04 & 960,688 & -- & -- \\
Mínimo & 28,42 & 44,69 & 960,166 & -- & -- \\
Médio & 29,14 & 47,69 & 960,427 & 2,435 & -- \\
Total & -- & -- & -- & -- & 67 \\
\hline
\end{tabular}

Fonte: INMET, 2018 
Conforme observado na tabela 2, houve uma precipitação de $67 \mathrm{~mm}$ distribuída nos dias 23/12 (50 mm), 08/01 (12mm) e 14/01 (5mm), nestes dias não foi contabilizado o volume de água gasto nos canteiros econômicos, uma vez que após as chuvas realizou-se a drenagem do excesso de água e o sistema de irrigação acionado pós 24 horas. Apesar do cultivo da alface ser limitada em função das variáveis climáticas de temperatura, umidade e chuva (Gomes et al., 2005), a temperatura, umidade e precipitação durante o experimento não afetaram o ciclo de desenvolvimento da alface, o desenvolvimento biométrico das variáveis número de folhas, altura da planta e diâmetro da planta ao longo dos dias após o transplantio para os canteiros econômico e convencional, estão apresentados na Figura 2. As lâminas de irrigação para ambos os canteiros, proporcionaram efeito exponencial do número de folhas até o vigésimo quarto dia após o transplantio e estabilizando-se aos 27 DAT, com uma média total de 28 folhas. planta $^{-1}$ (Figura 2a). Esse quantitativo final de número de folhas, foi considerado satisfatório, pois é uma característica importante, devido esta ser a parte comercial da cultura e também pela preferência do consumidor sobre aquelas alfaces que contenham um maior quantitativo de folhas por planta (Filgueira, 2008; Diamante et al., 2013).

Para a altura da planta, observa-se que assim como o número de folhas, também houve um comportamento exponencial com valores semelhantes para os dois canteiros até o vigésimo dia após o transplantio. Após esse período, as alfaces do canteiro econômico obtiveram alturas superiores à do canteiro convencional, com $22 \mathrm{~cm}$ e $19 \mathrm{~cm}$, respectivamente, aos 27 DAT (Figura 2b).

Em relação ao diâmetro da planta, verificou-se uma regressão quadrática para ambos os canteiros, com diâmetro mínimo de $14,5 \mathrm{~cm}$ aos 4 DAT e máximo de 43 e $40 \mathrm{~cm}$ para o canteiro econômico e convencional, respectivamente, conforme (Figura 2c). O diâmetro da planta tem influência direta na produtividade, o qual a fotossíntese pode ser afetada em razão da área foliar que recebe a energia luminosa e sua conversão em energia química (Taiz \& Zeiger, 2009). Isso pode estar associado as condições climáticas (fotoperíodo e temperatura) durante a condução do experimento, bem como a natureza genética do material, que por razão, poderão alterar o metabolismo da planta.

Apesar do consumo de água ter sido maior nos canteiros econômicos irrigados com o sistema de irrigação cuca de umbu, conforme mostrado na figura 3, percebe-se a partir dos dados apresentados na figura 2 que o número de folhas, a altura e o diâmetro da planta foram melhores nestes canteiros.

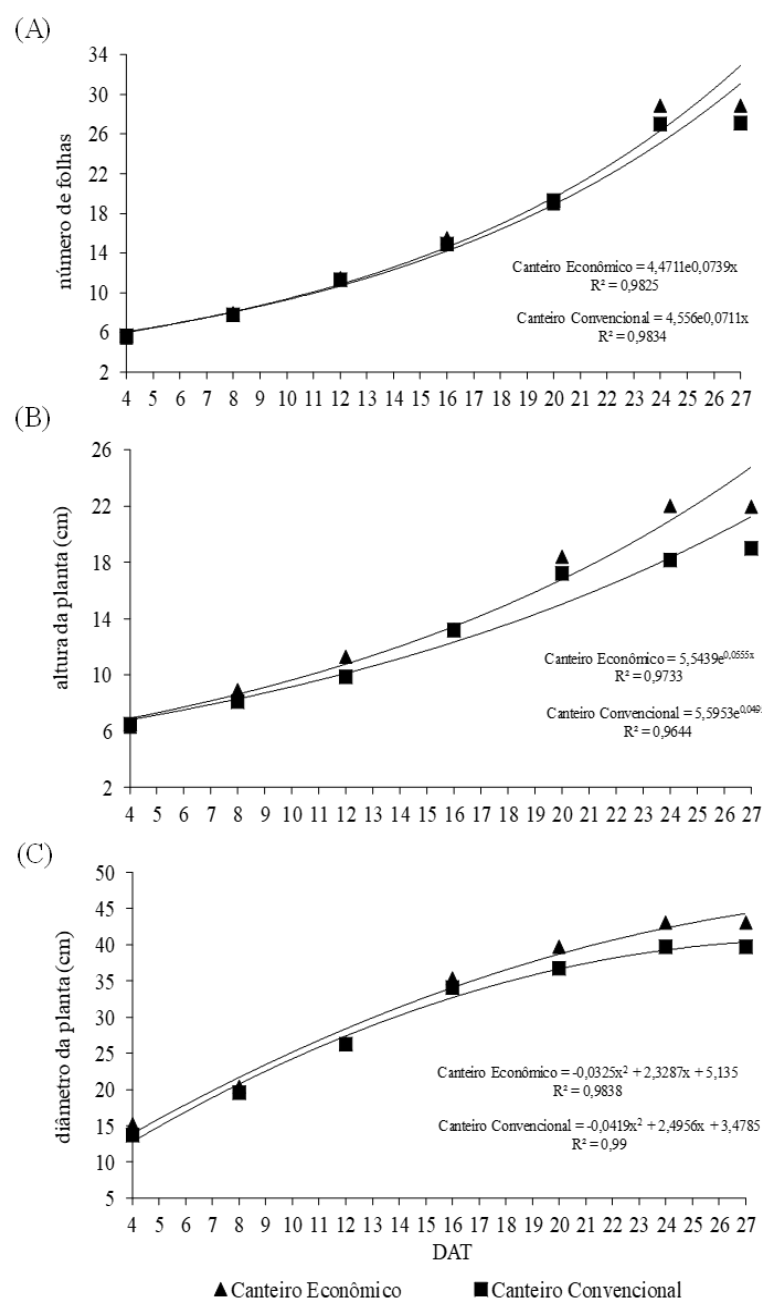

Figura 2. Número de folhas (A), altura da planta (B) e diâmetro da planta (C) de alface venerada, cultivada em canteiro econômico e convencional.

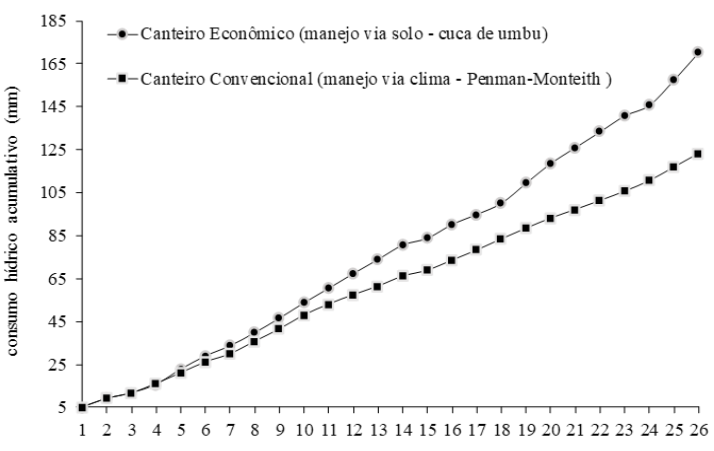

DAT

Figura 3. Consumo hídrico acumulativo da alface $c v$. Veneranda em pelo manejo da irrigação em (canteiro econômico via solo, pelo condutor hidráulico) e (canteiro convencional via ETo pelo método padrão de Penman-Monteith - FAO. 
Esta constatação mostra que sistemas de irrigação intermitentes podem ser muito úteis para a produção de alface no semiárido brasileiro, onde as temperaturas são altas e, por isso, hortaliças de clima frio como a alface, por exemplo, transpiram muito e de forma muito mais rápida se comparado a sua região de origem, onde o produtor pode demorar mais tempo para irriga-las.

Neste sentido, o sistema de irrigação cuca de umbu pode ser muito útil para pequenos produtores do semiárido por ser um sistema de fácil confecção e manejo da água, porém carece de trabalhos futuros no sentido de aumentar a sua eficiência.

\section{Conclusão}

O desenvolvimento biométrico da alface foi melhor no sistema de irrigação cuca de umbu, embora neste sistema o consumo de água tenha sido maior quando comparado ao manejo da irrigação via clima utilizando o método padrão de Penman-Monteith - FAO.

$\mathrm{O}$ uso do canteiro econômico integrado ao sistema de irrigação cuca de umbu torna-se uma ferramenta de manejo da água sem complexidade para agricultores de base familiar no semiárido pernambucano. Porém, se faz necessário a realização de trabalhos futuros com o intuito de aumentar a sua eficiência.

\section{Referências}

Allen, R. G., Pereira, L. S., Raes, D. \& Smith, M. 1998. Crop evapotranspiration: Guidelines for computing crop water requirements. Rome: FAO. 300 p. (FAO - Irrigation and Drainage, Paper, 56.

Araújo Filho, J.C., Burgos, N., Lopes, O.F., Silva, F.H.B.B., Medeiros, L.A.R., Melo Filho, H.F.R., Parahyba, R.B.V., Cavalcanti, A.C., Oliveira Neto, M.B., Silva, F.B.R., Leite, A.P., Santos, J.C.P., Sousa Neto, N.C., Silva, A.B., Luz, L.R.Q.P., Lima, P.C., Reis, R.M.G. \& Barros, A.H.C. 2000. Levantamento de reconhecimento de baixa e média intensidade dos solos do Estado de Pernambuco. Rio de Janeiro: Embrapa Solos. (Boletim de Pesquisa; 11).

Bonela, G. D., Souza, H. O., Guimarães, R. R. \& Gomes, E. J. C. 2015. Resposta de cultivares de alface a diferentes fontes de matéria orgânica. Revista Brasileira de Agropecuária Sustentável, 5(2), 89-95.

Costa, K. D. S., Carvalho, I. D. E., Ferreira, P. V., Silva, J. \& Teixeira, J. S. 2012. Avaliação de substratos alternativos para a produção de mudas de alface. Revista Verde, 7(5), 58-62.
Diamante, M. S., Santino Junior, S., Inagaki, A. M., Silva, M. B. \& Dallacort, R. 2013. Produção e resistência ao pendoamento de alfaces tipo lisa cultivadas sob diferentes ambientes. Revista Ciência Agronômica, 44(1), 133-140.

Favarato, L. F., Guarçoni, R. C. \& Siqueira, A. P. 2017. Produção de alface de primavera/verão sob diferentes sistemas de cultivo. Revista Científica Intelletto, 2(1), 16-28.

Feltrin. Alface Veneranda. Disponível em: $<$ https://www.sementesfeltrin.com.br/Produto/ alface\%20veneranda?peletizada=peletizada $>$. Acesso em: 10 de novembro de 2017.

Filgueira, F. A. R. 2008. Manual de olericultura: cultura e comercialização de hortaliças. 3 ed. Viçosa: UFV. 421p.

Gomes, T. M., Botrel, T. A., Modolo, V. A. \& Oliveira, R. F. 2005. Aplicação de CO2 via água de irrigação na cultura da alface. Horticultura Brasileira, 23, 316-319.

INMET, Instituto Nacional de Meteorologia. 2018. Dados da estação climática de Salgueiro/PE. Disponível em: http://www.inmet.gov.br/sonabra/pg_dspDado sCodigo_sim.php?QTM3MA. Acesso em: 23 de julho, 2018.

Juchen, C. R., Suszek, F. L. \& Vilas Boas, M. A. 2013. Irrigação por gotejamento para produção de alface fertirrigada com águas residuárias agroindustriais. Revista Irriga, 18(1), 243-256.

Lewis, G. P. 1987. Legumes of Bahia. Royal Botanic Garden, Kew. Inglaterra. 369p.

Leite, D. C., Oliveira, R. H. \& Júnior, G. B. 2011. Eficiência do uso da água em sistema alternativo de irrigação na produção de mudas de alface. Cadernos de Agroecologia, 6(2), 1-5.

Penna, J. F. M. 1946. Dicionário brasileiro de plantas medicinais. 3. Ed. Rio de Janeiro: Kosmos.

Pio Corrêa, M. 1984. Dicionário das plantas uteis do Brasil. Rio de Janeiro: Imprensa Nacional. 687 p.

Sediyama, M. A. N., Santos, I. C. \& Lima, P. C. 2014. Cultivo de hortaliças no sistema orgânico. Revista Ceres, 61, 829-837.

Souza, J. L. \& Resende, P. 2006. Manual de Horticultura Orgânica. 2.ed. atualizada e ampliada - Viçosa, MG: Aprenda Fácil. 843 p.

Taiz, L. \& Zeiger, E. 2009. Plant physiology. 3.ed. Porto Alegre: Artmed. 719p.

Recebido: 23 Julho, 2018

Aprovado: 16 Agosto, 2018

Publicado: 28 Setembro 2018

Licenciamento: Este artigo é publicado na modalidade Acesso Aberto sob a licença Creative Commons Atribuição 4.0 (CC-BY 4.0), a qual permite uso irrestrito, distribuição, reprodução em qualquer meio, desde que o autor e a fonte sejam devidamente creditados. 